\title{
Diversity of insects associated with olive (Oleaceae) groves across a dryland climate gradient in Algeria- ERRATUM
}

\author{
Smail Chafaa, Fateh Mimeche, and Haroun Chenchouni
}

https://doi.org/10.4039/tce.2019.35. Published online by Cambridge University Press, 5 July 2019

Owing to a printer's error, Smail Chafaa's affiliation was incorrectly listed in the original online version of the article by Chafaa et al. (2019) (first published online 5 July 2019). In addition, the superscript numeral 2 in the Haroun Chenchouni's second affiliation was omitted. The affiliations should be listed as follows:

S. Chafaa, Department of Ecology and Environment, Faculty of Natural and Life Sciences, University of Batna 2, 05078 Fesdis, Batna, Algeria

H. Chenchouni, ${ }^{1}$ Department of Natural and Life Sciences, Faculty of Exact Sciences and Natural and Life Sciences, University of Tebessa, 12002 Tebessa, Algeria; ${ }^{2}$ Laboratory of Natural Resources and Management of Sensitive Environments "RNAMS," University of Oum-El-Bouaghi, 04000 Oum-El-Bouaghi, Algeria

These errors have been corrected online and in print.

We regret these errors.

\section{Reference}

Chafaa, S., Mimeche, F., and Chenchouni, H. 2019. Diversity of insects associated with olive (Oleaceae) groves across a dryland climate gradient in Algeria. The Canadian Entomologist. 151: 629-647. https://doi.org/10.4039/ tce. 2019.35 